\title{
The Physical Quality and Microstructure of Symbiotic Yogurt Fortified with Inulin at Various pH Values
}

\author{
Manik Eirry Sawitri ${ }^{1 *}$, Djalal Rosyidi ${ }^{2}$, Lilik Eka Radiati ${ }^{2}{\text { and } \text { Purwadi }^{2}}^{2}$ \\ ${ }^{1}$ Post Graduate Program, Faculty of Animal Husbandry, Brawijaya University, \\ Malang, East Java, Indonesia \\ ${ }^{2}$ Department of Animal Food Technology, Faculty of Animal Husbandry, Brawijaya \\ University, Malang, East Java, Indonesia
}

*Corresponding author

\section{A B S T R A C T}

\section{Keywords}

Inulin, Symbiotic

yogurt, Physical

quality,

Microstructure

\section{Article Info}

Accepted:

10 December 2017

Available Online:

10 January 2018
This research revealed the effect of inulin addition towards the quality of observed symbiotic yogurt. The symbiotic yogurt fortified with $2 \%$ of inulin was being analyzed in relation to its physical quality (emulsion stability, emulsion activity, viscosity, syneresis and water holding capacity) and microstructure at various $\mathrm{pH}$ values: $\mathrm{pH}$ (1) 5.0, $\mathrm{pH}$ (2) 4.5 and $\mathrm{pH}$ (3) 4.0. The decrease of $\mathrm{pH}$ in the symbiotic yogurt gave a significant difference $(P<0.05)$ to the average of emulsion stability, yet it gave a very significant difference $(\mathrm{P}<0.01)$ to the average emulsion activity, viscosity, syneresis and water holding capacity. The decrease of yogurt $\mathrm{pH}$ and the addition of inulin gave a higher average of emulsion stability, emulsion activity, viscosity and water holding capacity than other treatment of yogurt $\mathrm{pH}$. Yogurt at a $\mathrm{pH}$ value of 5.0 produced a lower emulsion stability, emulsion activity, viscosity and syneresis, but it had a higher water holding capacity. When $\mathrm{pH}$ value was below the isoelectric $\mathrm{pH}$ (pH 4.5 and 4.0), it increased the emulsion stability, emulsion activity, viscosity and syneresis and decreased yogurt water holding capacity. The microstructure of yogurt symbiotic indicated that the addition of inulin strengthened the gel network formed so that the structure of yogurt could inhibit syneresis and excessive permeability, and provided a more refined, compact and identical structure.

\section{Introduction}

Functional food products such as yogurt in the last decade have been fortified with prebiotics, especially fibers, into their formulations; it works in addition to the purpose of increasing the activity and viability of probiotic (Grajek et al., 2005). It also increases the quality of yogurt so that it can be accepted by consumers, in line with the healthy lifestyle and pattern of society. Yogurt is often defective due to the increasing of syneresis during storage which is resulting in the decreasing of its physical quality and leading to the less acceptable yogurt by consumers (Mazloomi et al., 2011). Protein in milk is mostly casein (80-85persen) which is dominant in almost all mammal species. 
Casein consists of $\alpha$ s 1 -casein, $\alpha$ s2-casein, $\beta$ casein, $\kappa$-casein and colloidal calcium phosphate (CCP) in the form of aggregates which is called as casein micelle (Lucey and Singh, 2003).

The main components as the primary building blocks of yogurt structure are the casein micelle (Lucey and Singh, 1997) and milk pH which becomes one of the major factors determining the formation of casein micelle structure resulting in viscoelastic yogurt (Karki, 2012). During acidification, casein micelles are dissociated, particularly in the $\mathrm{pH}$ range 5.5 to 5.0 , due to the dissolution of colloidal calcium phosphate (CCP) (Lucey and Singh, 2003). Inulin added to yogurt will form dispersion between casein micelles (Paseephol et al., 2008).

Inulin naturally contains fructooligosaccharide and has properties as a fiber (Akin et al., 2007) that will interact with a positive charge on the surface of casein micelles to strengthen casein network and reduce syneresis in yogurt (Hematyar et al., 2012). Inulin in dairy products can have a positive effect on emulsion stability, prevent phase separation, and improve yogurt physiochemistry (Montanuci et al., 2012). The combination of probiotics and prebiotics resulting in a relationship calls as symbiotic (Allgeyer et al., 2010) that will stimulate the growth of beneficial bacteria (Shaghaghi et al., 2013).

The first consumer assessment of a product acceptance is its invisible physical quality, and yogurt prioritizes the physical attribute which is the most important parameter for consumers (Allgeyer et al., 2010).

The objectives of this study were to study the physical quality (emulsion stability, emulsion activity, viscosity, syneresis, and water holding capacity) and microstructure of inulinfortified symbiotic yogurt.

\section{Materials and Methods}

\section{Ingredients}

The following ingredients: skimmed milk powder, inulin (CV. Gamma Scientific Biolab), a standard yogurt culture starter containing Lactobacillus bulgaricus FNCC0041 and Streptococcus thermophilus FNCC0040 were obtained from the Food and Nutrition Study Center of Gajah Mada University with a ratio of 1: $1(\mathrm{v} / \mathrm{v})$.

\section{The analysis of physical quality of symbiotic yogurt}

Here was the list of method and tools used to perform an analysis of symbiotic yogurt's physical quality: for the physical qualities of observed symbiotic yogurt (rotational viscometer brand Elcometer 2300), syneresis and water holding (modified centrifugation method) (Harwalkar and Kalab, 1981), emulsion stability (Sabah El-Kheir et al., 2008) and emulsion activity (Zheng and Jiang, 2014) and microstructures (Confocal Laser Scanning Microscopy/ CLSM) (Supavititpatana et al., 2009).

\section{The analysis of emulsion stability and emulsion activity}

Prepared $5 \mathrm{ml}$ of soybean oil, added $15 \mathrm{ml}$ sample, homogenized it with mixer for 1 minute, and then took $0.1 \mathrm{ml}$ at zero minute and $0.1 \mathrm{ml}$ for next 10 minutes. $0.1 \mathrm{ml}$ of solution taken was being dissolved with SDS $0.1 \%$ by $100 \mathrm{ml}$, stirred for 1 minute and it was inserted as much as $3 \mathrm{ml}$ into cuvette. Cuvette was inserted into a calibrated spectrophotometer. The reading of the spectrophotometer was with an absorbance of $500 \mathrm{~nm}$. The emulsion stability was calculated by using the following formula:

Emulsion stability $(\%)=\mathrm{A}_{10} / \mathrm{A}_{0} \times 100$ 
Note:

$\mathrm{A}_{0}=$ The absorbance value is seen with $\mathrm{A}=$ $500 \mathrm{~nm}$ at 0 minute

$\mathrm{A}_{10}=$ The absorbance value is seen with $\mathrm{A}=$ $500 \mathrm{~nm}$ at 10 minutes

The activity of the emulsion was calculated by using the formula of Zheng and Jiang (2014):

Emulsion Activity $\left(\mathrm{m}^{2} / \mathrm{g}\right)=(2 \times 2.303 \times \mathrm{A} \mathrm{x}$ DF) / I $\phi \mathrm{C}$

Note:

$\mathrm{A}=$ The absorbance value seen with $\mathrm{A}=500$ $\mathrm{nm}$

$\mathrm{DF}=$ Dilution factor $(100)$

$\mathrm{I}=$ Cuvette length

$\phi=$ Oil volume

$\mathrm{C}=$ Sample concentration

The analysis of syneresis and water holding capacity modified with centrifugation method

The $5 \mathrm{~g}$ of yogurt was weighed then it was inserted into a centrifugation tube. After that, it was centrifuged at 2240, 2560 and $2880 \mathrm{rpm}$ each for 10 minutes at room temperature. Whey was separated, collected and weighed at every centrifugation. The cumulative percentage $(\mathrm{w} / \mathrm{w})$ of whey was plotted by centrifugation force and the initial regression line slope was used as the coefficient of susceptibility to syneresis. Syneresis tendency was calculated by using the formula:

$\mathrm{X} \times 100 \%$ Syneresis/ Water Holding Capacity $=$
In which X: weight of whey; Y: initial weight of the sample.

The susceptibility of syneresis to centrifugation rate was calculated by using the formula:

Slope $=(A: B)$

In which A: speed of centrifugation (2240, 2560, 2880); B: the syneresis of each treatment in 3 centrifugation velocities.

\section{Statistical analysis}

The data were analyzed by using variance analysis (ANOVA). It employed the utilization of software to evaluate the effect of inulin addition on the physical quality of symbiotic yoghurt. The images of microstructural observations using casein with inulin were analyzed qualitatively by comparing all treatments to see the structures formed.

\section{Results and Discussion}

\section{Physical quality of symbiotic yogurt}

The average of physical quality (emulsion stability, emulsion activity, viscosity, syneresis, water holding capacity) of symbiotic yogurt is shown in Table 1.

The average emulsion stabilities of symbiotic yogurt at various $\mathrm{pH}$ values (1) $5.0, \mathrm{pH}$ (2) 4.5 and $\mathrm{pH}(3)$ were $61.02,84.85$ and $90.23(\%)$ respectively. The average activity of a symbiotic yogurt emulsions at various $\mathrm{pH}$ values were $1.81,1.94$ and $2.90(\mathrm{~m} 2 / \mathrm{g})$ respectively. The average viscosity of symbiotic yogurt at various $\mathrm{pH}$ values was $746.00,785.00$ and $1068.33(\mathrm{cP})$ respectively. The average syneresis of symbiotic yogurt at various $\mathrm{pH}$ values was $0.012,0.021$ and 0.023 respectively. The average of water holding 
capacity of symbiotic yogurt at various $\mathrm{pH}$ values was 66.59, 55.57 and 44.32 (\%) respectively.

Yogurt at higher $\mathrm{pH}$ value $(\mathrm{pH}$ 5.0) lead to emulsion stability, emulsion activity, viscosity and lower syneresis yet a higher water holding capacity. When the $\mathrm{pH}$ was below the isoelectric $\mathrm{pH}(\mathrm{pH} 4.5$ and 4.0), there was an increasing of emulsion stability, emulsion activity, viscosity and syneresis and the decrease of water holding capacity.

The possible interactions between casein and inulin consist of hydrogen bonding and hydrophobic interactions (Povolny and Smith, 2002). The addition of 2-3\% inulin enhances the emulsion stability and had a good stability under low acid condition (Ly et al., 2008). The decreasing of yogurt $\mathrm{pH}$ caused the formed gelation to grow strong and solid so that the average value of emulsion activity would be increase. The polymerization of some food proteins by transglutaminase improves the activity of emulsions rather than pure proteins at 4 to $6 \mathrm{pH}$ intervals (Motoki et al., 1984).

When the $\mathrm{pH}$ value of yogurt was higher than isoelectric $\mathrm{pH}$ (pI-4, 6), casein micelle undergone a CCP release and casein micelle dissociation, but the formation of casein micelle aggregate had not been strong yet. So, the ability of casein micelle to hold water was still high, thus resulting in a lower syneresis and viscosity.

While, the low stability and emulsion activity caused by aggregate formation that had not reached its upmost condition would be resulted in the possibility of a lower fat absorbance ability of casein micelle.

Table.1 The average of physical quality of symbiotic yogurt enriched with inulin

\begin{tabular}{|l|l|l|l|l|l|}
\hline pH & $\begin{array}{l}\text { Emulsion } \\
\text { stability }(\%)\end{array}$ & $\begin{array}{l}\text { Emulsion } \\
\text { activity }\left(\mathrm{m}^{2} / \mathrm{g}\right)\end{array}$ & $\begin{array}{l}\text { Viscosity } \\
(\mathrm{cP})\end{array}$ & Syneresis & $\begin{array}{l}\text { Water holding } \\
\text { capacity }(\%)\end{array}$ \\
\hline pH (1)5.0 & $61.02^{\mathrm{x}}$ & $1.81^{\mathrm{a}}$ & $746.00^{\mathrm{a}}$ & $0.012^{\mathrm{a}}$ & $66.59^{\mathrm{a}}$ \\
\hline pH (2)4.5 & $84.85^{\mathrm{xy}}$ & $1.94^{\mathrm{a}}$ & $785.00^{\mathrm{a}}$ & $0.021^{\mathrm{b}}$ & $55.57^{\mathrm{b}}$ \\
\hline pH (3)4.0 & $90.23^{\mathrm{y}}$ & $2.90^{\mathrm{b}}$ & $1068.33^{\mathrm{b}}$ & $0.023^{\mathrm{b}}$ & $44.32^{\mathrm{c}}$
\end{tabular}

Description: A different superscript ab in the same column indicated very significant difference $(\mathrm{P}<0.01)$. A different superscript $x y$ on the same column indicated that there was a significant difference $(P<0.05)$

Fig.1 The microstructures of symbiotic yogurt enriched with inulin

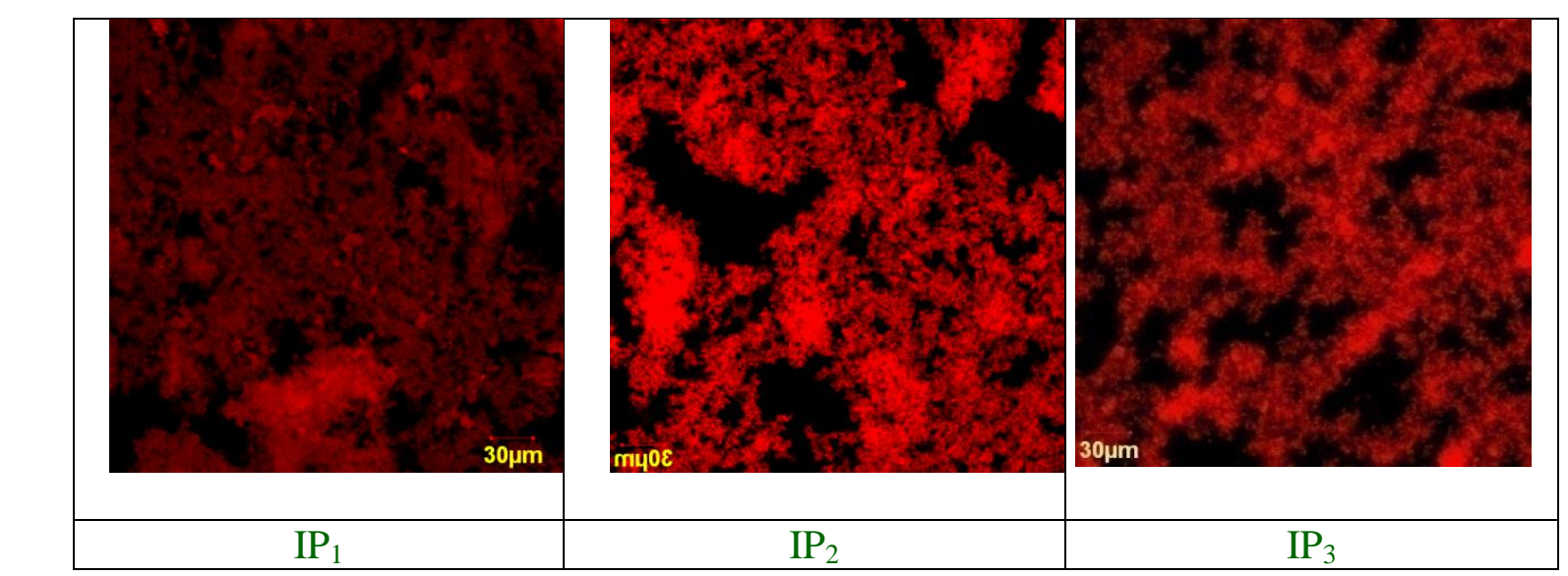

Note: I: Inulin P1:pH(1) 5.0 P2:pH(2) 4.5 P3:pH(3) 4.0 
At a lower $\mathrm{pH}$ value than the isoelectric $\mathrm{pH}$, casein micelles were aggregated as a result of electrostatic interaction between each casein micelle so that the water holding capacity of casein micelles decreases causing more susceptibility to syneresis and viscosity to be higher, while increased stability and emulsion activity may be caused by aggregates formed to allow casein micelles to have a higher fat absorbing capacity.

The role of added inulin into yogurt was to prevent gel weakening and maintain water holding ability through a symbiosis between inulin as prebiotic and lactic acid bacteria from yogurt starter as probiotics.

Inulin that enriched symbiotic yogurt acted as a thickener that forms a complex through a hydrogen bridge with a protein that will contribute to the intensification of viscosity (Rinaldoni et al., 2012). Yogurt that containing starter will decrease syneresis if it is enriched with stabilizer (Boeni and Pourahmad, 2012). Low-fat plain yogurt with added inulin can reduce the occurrence of syneresis (Aryana et al., 2007) and it is recommended using prebiotics to reduce syneresis (Aghajani et al., 2014). Inulin has the ability to bind water molecules and formed a network of gel particles (Franck, 2002) and the addition of inulin stabilizers can overcome the decrease of water holding capacity due to stabilizer function as a bridge between casein molecules and lactic acid molecules (Sawitri et al., 2008). Inulin has a hygroscopic nature that has the ability to bind water, water molecules becomes immobilized and cannot move freely among the other molecules of substances in the mixture (Akin et al., 2007).

The microstructures of casein and inulin at different $\mathrm{pH}$ values appeared as in Figure 1. By conducting an observation using CLSM, the protein phase appeared as a bright area while inulin could not be visualized under these conditions. Skim milk as raw material of symbiotic yogurt and inulin addition increased the total solids so that the interaction between the casein particles would increase as well as the density of the matrix that was also increased. The casein gel formed by an increasing of $\mathrm{pH}$ value indicated that the microstructural improvement gained a better microstructure and the small pores between the protein grains became identical. Inulin as a stabilizer can prevent the precipitation of proteins especially at the isoelectric point; this inhibition is obtained due to the formation of complexes of polysaccharide proteins (Lee and Lucey, 2010). An active starter yogurt produces a homogeneous gel network structure and small pore size (Supavititpatana et al., 2009).

The results revealed that a symbiotic yogurt which was enriched with $2 \%$ of inulin, would have an improved physical quality in terms of emulsion stability, emulsion activity, viscosity, syneresis and water holding capacity at various $\mathrm{pH}$ values. The microstructure of a symbiotic yogurt which was fortified with $2 \%$ of inulin had a more unified, identical, and smaller pores size structure at various $\mathrm{pH}$ values.

\section{References}

Aghjani, A. R., R. Pourahmad and H. R. M. Adeli. 2014. The Effect of Oligofructose, Lactulosa and Inulin Mixture as Prebiotic on Physicochemical Properties of Synbiotic Yogurt. Journal of Food Biosciences and Technology, 4 (2): 3340.

Akin, M. B., M. S. Akin and Z. Kirmaci. 2007. Effects of Inulin and Sugar Levels on the Viability of Yogurt and 
Probiotic Bacteria and the Physical and Sensory Characteristics in Probiotic Ice Cream. Journal Food Chemistry 104: 93-99.

Allgeyer, L. C., M. J. Miller and S.Y. Lee. 2010. Sensory and Microbiological Quality of Yogurt Drinks with Prebiotics and Probiotics. Journal of Dairy Science 93 (10): 4471-4479.

Aryana, K. J., S. Plauche, R. M. Rao, P. Mc. Grew and N. P. Shah. 2007. Fat-Free Plain Yogurt Manufactured with Inulins of Various Chain Lengths and Lactobacillus acidophilus. Journal of Food Science. 72 (3):79-84.

Boeni, S and R. Pourahmad. 2012. Use of Inulin and Probiotic Lactobacilli in Synbiotic Yogurt Production. Scholars Research Library Annals of Biological Research. 3 (7): 3486-3491.

Franck, A. 2002. Technological Functionality of Inulin and Oligofructose. British Journal of Nutrition, 2: 287-291.

Grajek, W., A. Olejnik and A. Sip. 2005. Probiotics, Prebiotics and Antioxidants as Functional Foods. Acta Biochemica Polonia. 52(3): 665-671.

Harwalkar V. R. and M. Kalab, 1981. Effect of Acidulant and Temperature on Microstructure, Fiemness, and Susceptibility to Syneresis of Skim Milk Gels in Hess, S.D., R.F. Roberts and G.R. Ziegler, 1997. Rheology Properties of Nonfat Yogurt Stabilized Using L. debrueckii ssp. Bulgaricus Producing Exopolysaccharide or Using Commercial Stabilizer Systems. J. Dairy Science 78:2624-2628.

Hematyar, N., A. M. Samarin, H. Poorazarang and A. H. Elhamirad. 2012. Effect of Gum on Yoghurt Characteristics. World Applied Sciences Journal 20 (5), 661665.

Karki, R. J. 2012. Comparative Study of the Physicochemical Properties of Low Fat yogurt Fortified with Different Chain
Length Inulins and Partially Hydrolyzed Guar Gum University of Wisconsin

Lee, W. J. and J. A. Lucey. 2010. Formation and Physical Properties of Yoghurt. Asian-Australia Journal Animal Science. 23 (9):1127-1136.

Lucey, J. A., and Singh., H. 1997. Formation and physical properties of acid milk gels: A review. Food Reseach International, 30:529-542.

Lucey, J.A. and Singh, H. 2003. Acid coagulation of milk. In advanced dairy chemistry, Vol. 2: proteins, 2nd edn. (eds. P.F. Fox and P.L.H. McSweeney), Aspen Publishers, Gaithersburg,: 9971021.

Ly, M.H., M. Aguedo., S. Goudot, M. L.Le, P. Cayot, J. A. Teixeira, T. M. Le, J. M. Belin, Y. Wache. 2008. Interaction Between Bacterial Surfaces and Milk Proteins, Impact on Food Emulsion Stability. Food Hydrocolloids 22:742751.

Mazloomi, S. M., S. S. Shekarforoush, H. Ebrahimnejad and J. Sajedianfard. 2011. Effect of Adding Inulin on Microbial and Physicochemical Properties of Low Fat Probiotic Yogurt. Iranian Journal of Veterinary Research, Shiraz University 12 (2): 93-98.

Montanuci, F. D., T. C. Pimentel, S. Garcia and S. H. Prudencio. 2012. Effect of Starter Culture and Inulin Addition on Microbial Viability, Texture and Chemical Characteristics of Whole or Skim Milk Kefir. Cienc. Tecnol. Aliment., Campinas 32(4):850-861.

Motoki, M., Nio, N., and Takinami, K. 1984. Functional Properties of Food Proteins Polymerized by Transglutaminase. Agric. Biol. Chem. 48(5):1257-1261.

Paseephol, T., Small, D. M., and Sherkat, F. 2008. Rheology and texture of set yogurt as affected by inulin addition. Journal of Texture Studies, 39(6): 617634. 
Povolny, S and Smith. 2002. Interaction of Milk Proteins with Inulin, Protein Carbohydrate Interaction. Milchwissenscahft. Pp. 494-497, http:// www.researchgate.net/publication/2796 24142

Rinaldoni, A. N., M. E. Campderros and A. P. Padilla. 2012. Physico-chemical and Sensory Properties of Yogurt from Ultrafiltreted Soy Milk Concentrate Added with Inulin. LWT-Food Science and Technology. 45:142-147.

Sabah El-Kheir, M.K., Yagoub, A.A and Abu Baker A.A 2008. Emulsion-Stabilizing effects of gum from Acacia senegal (L) Willd. The role of Quality and grade of gum, oil type, Temperature, stirring time and concentration. Pakistan Journal of Nutrition, 7(3): 395-399.

Sawitri, M. E., A. Manab, T. W. L. Palupi. 2008. Kajian Penambahan Gelatin Terhadap Keasaman, pH, Daya Ikat Air dan Sineresis Yoghurt. Jurnal Ilmu dan Teknologi Hasil Ternak. 3 (1): 35-42.

Shaghaghi, M., R. Pourahmad and H. R. M. Adeli. 2013. Synbiotic Yoghurt Production by Using Prebiotic Compounds and Probiotic Lactobacilli. International Research Journal of Applied and Basic Sciences. 5(7): 839846.

Supavititpatana P., T. I. Wirjantoro, and P. Raviyan, 2009. Effect of Sodium Caseinate and Whey Protein Isolate Fortification on the Physical Properties and Microstructure of Corn Milk Yogurt. CMU Journal Nat. Science, 8(2): 247-263.

Zheng, M, Z. B. Jia and J. X. Jiang. 2014. Emulsfying and Foaming Properties of Soy Protein Isolate with Covalent Modification by (-)-Epigallocatechin-3Gallate. Advance Journal of Food Science and Technology, 6 (2): 238-240

\section{How to cite this article:}

Manik Eirry Sawitri, Djalal Rosyidi, Lilik Eka Radiati and Purwadi. 2018. The Physical Quality and Microstructure of Symbiotic Yogurt Fortified with Inulin at Various $\mathrm{pH}$ Values. Int.J.Curr.Microbiol.App.Sci. 7(01): 1052-1058. doi: https://doi.org/10.20546/ijcmas.2018.701.126 